\title{
EKSPERIMENTASI MODEL PEMBELAJARAN THINK-PAIR- SHARE (TPS), THINK-TALK-WRITE (TTW) DAN TWO STAY- STRAY (TSTS) PADA MATERI BANGUN RUANG SISI DATAR DITINJAU DARI SELF-EFFICACY
}

\author{
Khafittulloh Viqriah $^{1}$, Budiyono $^{2}$, Sri Subanti ${ }^{3}$ \\ ${ }^{1,2,3}$ Prodi Magister Pendidikan Matematika, FKIP Universitas Sebelas Maret Surakarta
}

\begin{abstract}
The aims of this research was to determine the effect of learning models on mathematics achievements and learning interest viewed from students selfefficacy. The learning model compared were TPS, TTW, and TSTS. The type of the research was a quasi-experimental research. The population were all of the students in grade $8^{\text {th }}$ of Junior High School in Sleman regency. Sampling was done by stratified cluster random sampling. The samples were students of SMPN 1 Kalasan, SMPN 4 Kalasan, and SMPN 2 Ngemplak. The instruments used were mathematics achievement tests and self-efficacy questionnaire. The data was analyzed by using unbalanced two-ways Anova. The conclusions were as follows. (1) TPS gives better mathematics achievement than TTW, and both gives better mathematics achievement than TSTS. (2) Students who have high and medium self-efficacy have the same mathematics achievement, students who have medium and low selfefficacy have the same mathematics achievement, students who have high selfefficacy was better than students who have low self-efficacy. (3) For TPS and TTW, students who have high, medium, and low self-efficacy have the same mathematics achievement. For TSTS, students who have high and medium self-efficacy have the same mathematics achievement, students who have medium and low self-efficacy have the same mathematics achievement, students who have high self-efficacy was better than students who have low self-efficacy. (4) For students who have high and medium self-efficacy, TPS,TTW, and TSTS gives the same mathematics achievement. For students who have low self-efficacy, TPS and TTW gives the same mathematics achievement, TPS gives better mathematics achievement than TSTS, and TTW gives better mathematics achievement than TSTS .

Keywords: Think-Pair-Share (TPS), Think-Talk-Write (TTW), Two Stay-Two Stray (TSTS), self-efficacy
\end{abstract}

\section{PENDAHULUAN}

Matematika merupakan salah satu disiplin ilmu yang tersusun dengan sistematis karena diberikan dari yang mudah ke yang sulit. Selain itu dalam matematika materi yang diberikan berkesinambungan, dari konsep dasar lalu dilanjutkan pengembangan konsep. Karena dalam pembelajaran matematika materi yang diberikan berkesinambungan, maka penguasaan konsep dasar sangatlah penting. Jika siswa tidak menguasai konsep dasar, maka siswa akan merasa kesulitan mempelajari materi yang berhubungan dengan konsep dasar tersebut, sehingga akan berakibat siswa merasa sulit dalam mempelajari matematika.

Rendahnya prestasi belajar matematika khususnya untuk siswa SMP di Kabupaten Sleman dapat dilihat pada hasil Ujian Nasional tahun 2013/2014. Salah satu materi matematika berdaya serap rendah adalah materi bangun ruang sisi datar. Hal ini ditunjukkan dengan persentase penguasaan materi bangun ruang sisi datar tingkat 
nasional sebesar 60,11\% sedangkan tingkat Kabupaten Sleman hanya 54,57\% (Badan Standar Nasional Pendidikan, 2014). Jika dibandingkan dengan daerah lain di provinsi Daerah Istimewa Yogyakarta, misalnya kotamadya Yogyakarta dengan persentase penguasaan materi bangun ruang sisi datar sebesar 61,35\%, maka Kabupaten Sleman lebih rendah daripada kotamadya Yogyakarta. Penguasaan materi tersebut juga lebih rendah jika dibandingkan dengan materi lain misalnya materi segitiga di tingkat nasional, provinsi, dan kabupaten berturut-turut yaitu 77,70\%, 95,65\%, dan 95,84\%.

Menurut Carol (Nana Sudjana, 2005: 40) salah satu hal yang dapat mempengaruhi prestasi belajar siswa adalah kualitas pembelajaran yang dilakukan oleh seorang guru. Kualitas pembelajaran yang dilakukan oleh seorang guru bisa berupa model pembelajaran yang digunakan oleh guru saat melakukan proses pembelajaran matematika. Prestasi matematika siswa yang masih kurang optimal kemungkinan disebabkan model pembelajaran yang digunakan oleh guru masih kurang tepat. Guru dalam proses pembelajaran seharusnya bisa menguasai beberapa model pembelajaran. Salah satu model pembelajaran yang ada adalah pembelajaran kooperatif. Menurut Abruscato (1996: 74) “A cooperative learning group consists of a group of children who are in fact working together on a project, are supportive of one another, and are accountable for their individual learning." Dengan pembelajaran kooperatif, siswa akan lebih aktif karena adanya kerja sama yang dilakukan antar kelompok dalam memecahkan suatu permasalahan. Hasil penelitian Artut (2010), dengan pembelajaran kooperatif terjadi peningkatan yang signifikan dalam hasil pembelajaran matematika. Springer, et. al (1999) melakukan penelitian mengenai efek pembelajaran secara kelompok, salah satunya dalam pembelajatan matematika. Hasil dari penelitian tersebut adalah ada berbagai tipe dalam model pembelajaran kooperatif, diantaranya adalah tipe Think-PairShare (TPS), Think-Talk-Write (TTW), dan Two Stay Two Stray (TSTS) yang mungkin dapat meningkatkan kemampuan siswa.

Pembelajaran TPS akan dapat mengoptimalkan partisipasi siswa (Miftahul Huda, 2011: 136). Dengan optimalnya partisipasi siswa nantinya diharapkan siswa menjadi lebih aktif dalam proses pembelajaran matematika, prestasi belajar siswa juga akan meningkat. Pembelajaran model kooperatif tipe TPS, menurut Arends, (1997: 122) dilaksanakan dengan beberapa tahap yaitu think (berpikir), pair (berpasangan), dan share (berbagi). Tipe pembelajaran kooperatif ini memungkinkan siswa untuk saling bertukar pendapat dan saling membimbing satu sama lain, sehingga dapat meningkatkan partisipasi siswa dalam kelompok kecil. Penelitian yang dilakukan Pandya (2011) menunjukkan bahwa dengan pembelajaran kooperatif tipe TPS dapat meningkatkan penacapaian prestasi akademik matematika siswa. Kitaoka (2013) meneliti bahwa dengan 
pembelajaran kooperatif TPS dapat meningkatkan prestasi daripada pembelajaran konvensional.

Selain pembelajaran kooperatif TPS guru juga bisa menggunakan pembelajaran kooperatif tipe TTW. Menurut Huinker dan Laughlin (1996:82)

The think-talk-write strategy builds in time for thought and reflection and for the organization of ideas and the testing of those ideas before students are expected to write. The flow of communication progresses from student engaging in thought or reflective dialogue with themselves, to talking and sharing ideas with one another, to writing.

Model pembelajaran TTW dapat membangun pemikiran, merefleksi, dan mengorganisasi ide, kemudian menguji ide tersebut sebelum peserta didik diharapkan untuk menulis. Pada pembelajaran model kooperatif tipe TTW ada tiga tahap penting, yaitu tahap think (siswa mencoba memikirkan permasalahan yang diberikan), talk (siswa mencoba mendiskusikan hasil pemikiran keteman sekelompoknya), dan tahap write (siswa mencoba menuliskan hasil diskusi dengan teman sekelompoknya). Dengan tahapantahapan pada TTW tersebut, diharapkan siswa menjadi lebih aktif dalam proses pembelajaran, sehingga nantinya prestasi belajar siswa akan dapat meningkat. Supriyono (2011) meneliti mengenai peningkatan prestasi belajar matematika menggunakan pembelajaran kooperatif tipe TTW. Penelitian menghasilkan dengan menggunakan TTW prestasi balajar matematika dapat meningkat.

Selain pembelajaran kooperatif tipe TPS dan TTW, guru juga bisa menggunakan pembelajaran kooperatif tipe Two Stay Two Stray (TSTS). Model pembelajaran ini dikembangkan oleh Spencer Kagan dan dapat digunakan dalam semua mata pelajaran dan untuk semua tingkatan usia anak didik (Lie, 2004: 61). Langkah-langkah melakukan model pembelajaran TSTS menurut Agus Suprijono (2009: 93-94) pertama siswa dibagi menjadi beberapa kelompok dengan tiap kelompok terdiri dari empat siswa, kemudian guru memberikan tugas yang harus mereka diskusikan jawabannya. Setelah diskusi intra kelompok usai, dua orang dari masing-masing kelompok meninggalkan kelompoknya untuk bertamu kepada kelompok lain dan anggota kelompok yang tidak mendapat tugas sebagai duta (tamu) mempunyai kewajiban menerima tamu dari suatu kelompok lain. Siswa yang bertugas menerima tamu, bertugas memaparkan hasil kerja kelompok dan informasi yang mereka miliki kepada tamu. Setelah selesai bertamu, siswa yang bertugas menjadi tamu kembali ke kelompok asal dan melaporkan temuan mereka dari kelompok lain. Setelah itu, kelompok mencocokkan dan membahas hasil kerja mereka. Dalam pembelajaran kooperatif tipe TSTS ini siswa memiliki kesempatan untuk mengemukakan pendapat yaitu saat memaparkan hasil diskusinya ke anggota kelompok lain, dan mengolah informasi yang didapat dan dapat meningkatkan keaktifan. Dwi Sulisworo dan Fadiyah Suryani (2014) meneliti jika pembelajaran kooperatif tipe TSTS dapat 
meningkatkan prestasi belajar. Tipe pembelajaran kooperatif ini memungkinkan siswa untuk dapat mengemukakan pendapatnya dengan lebih baik lagi sehingga memungkinkan siswa untuk dapat meningkatkan hasil belajarnya.

Faktor lain yang mungkin dapat mempengaruhi hasil belajar siswa adalah selfefficacy. Menurut Bandura, self-efficacy adalah keyakinan seseorang bahwa dirinya memiliki kemampuan untuk melakukan tugas tertentu (Karsten dan Roberta, 1998: 62). Bagi siswa, keyakinan dalam mengerjakan soal-soal matematika sangatlah penting. Dengan adanya keyakinan yang mantap bagi siswa dimungkinkan kemampuankemampuan yang dimiliki siswa seperti hasil belajar siswa, akan dapat berkembang lagi dengan lebih maksimal, sehingga self-efficacy sangat berpengaruh dalam hasil belajar siswa. Siswa dengan self-efficacy tinggi cenderung akan berusaha lebih maksimal dalam mengomunikasikan pendapatnya sehingga nantinya akan mendapatkan hasil yang lebih baik daripada siswa dengan self-efficacy rendah. Siswa sering dihadapkan oleh rasa tidak yakin ketika mengerjakan soal-soal matematika. Zimmerman (2000) meneliti tentang self-efficacy dalam pemecahan masalah matematika. Temuan dalam penelitian tersebut adalah dengan baiknya self-efficacy maka lebih baik pula kemampuan pemecahan masalah matematikanya. Pajares (1996) meneliti mengenai self efficacy dalam dunia pendidikan. Dalam penelitiannya diperoleh bahwa self-efficacy sangat berpengaruh dalam dunia pendidikan. Judge, et. al (2007) meneliti Sef-Efficacy dan kemampuan bekerja dilihat dari perbedaan tiap individu. Dalam penelitian ini diapaparkan bahwa self-eficacy mempunyai kontribusi yang berbeda-beda di tiap orang saat mereka sedang bekerja. Berdasarkan penelitian yang sebelumnya, diduga self-efficacy dapat mempengaruhi prestasi belajar matematika siswa.

Penelitian ini bertujuan untuk mengetahui: (1) manakah yang memberikan prestasi belajar lebih baik antara model pembelajaran kooperatif tipe TPS, TTW atau TSTS; (2) manakah siswa yang mempunyai prestasi belajar lebih baik antara siswa dengan self-efficacy tinggi, sedang, atau rendah; (3) pada masing-masing model pembelajaran, manakah yang memberikan prestasi belajar lebih baik antara siswa dengan self-efficacy tinggi, sedang, atau rendah; (4) pada masing-masing kategori self-efficacy siswa, manakah yang memberikan prestasi belajar lebih baik, model pembelajaran kooperatif tipe TPS, TTW atau TSTS.

\section{METODE PENELITIAN}

Jenis penelitian ini adalah penelitian eksperimental semu (quasi experimental) dengan rancangan faktorial $3 \times 3$. Populasi dalam penelitian ini adalah seluruh siswa kelas VII SMP Negeri se-Kabupaten Sleman tahun pelajaran 2014/2015. Populasi terdiri 
dari 45 SMP Negeri yang tersebar di wilayah Kabupaten Sleman. Teknik pengambilan sampel yang digunakan dalam penelitian ini adalah teknik stratified cluster random sampling. Dari sampling yang dilakukan diperoleh sampel yaitu SMPN 1 Kalasan, SMPN 4 Kalasan, dan SMPN 2 Ngemplak.

Terdapat dua variabel bebas dalam penelitian ini yaitu model pembelajaran dan self-efficacy, serta satu variabel terikat yaitu prestasi belajar matematika. Metode pengumpulan data menggunakan metode tes, angket, dan dokumentasi. Instrumen yang digunakan dalam penelitian ini adalah instrumen tes prestasi belajar matematika dan angket self-efficacy. Soal tes prestasi belajar matematika terdiri dari 20 soal pilihan ganda. Angket self-efficacy siswa terdiri dari 35 pernyataan dengan rincian 19 pernyataan bernilai positif $(+)$ dan 16 pernyataan bernilai negatif (-).

Teknik analisis data yang digunakan untuk menguji hipotesis dalam penelitian ini adalah analisis variansi dua jalan dengan sel tak sama pada taraf signifikansi 0,05 . Uji prasyarat terhadap data kemampuan awal matematika siswa meliputi uji normalitas dengan menggunakan uji Lilliefors dan uji homogenitas variansi menggunakan uji Bartlett. Selanjutnya dilakukan uji keseimbangan dengan analisis variansi satu jalan untuk mengetahui apakah populasi dalam keadaan seimbang atau tidak. Uji hipotesis menggunakan analisis variansi dua jalan dengan sel tak sama dan uji lanjut pasca anava menggunakan metode Scheffe.

\section{HASIL PENELITIAN DAN PEMBAHASAN}

Dari hasil uji normalitas terhadap data kemampuan awal siswa, diperoleh bahwa nilai $L_{o b s}$ kelompok TPS, TTW, dan TSTS masing-masing kurang dari $L_{0,05}$. Hal ini berarti bahwa hipotesis nol $\left(H_{0}\right)$ diterima. Kesimpulannya, masing-masing kelas berasal dari populasi yang berdistribusi normal. Demikian pula hasil uji homogenitas variansi populasi terhadap data kemampuan awal siswa, diperoleh $\chi^{2}{ }_{o b s}=5,8322$ dengan $D K$ (daerah kritis) $=\left\{\chi^{2} \mid \chi^{2}>\chi_{0,05 ; 3-1}^{2}\right\}=\left\{\chi^{2} \mid \chi^{2}>5,9915\right\}$. Karena $\chi_{\text {obs }}^{2}$ berada di luar daerah kritis, maka $H_{0}$ diterima. Oleh karena itu, dapat disimpulkan bahwa ketiga kelompok sampel mempunyai populasi dengan variansi kemampuan awal yang sama.

Berdasarkan hasil uji keseimbangan terhadap data kemampuan awal matematika siswa, diperoleh $F_{\text {obs }}=0,8922$ dengan $D K=\{F \mid F>3,0296\} . F_{o b s}$ berada di luar daerah kritis, sehingga $H_{0}$ diterima dan disimpulkan bahwa ketiga kelompok mempunyai 
rerata kemampuan awal yang sama. Dengan demikian diperoleh kesimpulan bahwa populasi dalam keadaan awal yang seimbang.

Untuk keperluan uji hipotesis, terlebih dahulu dilakukan uji normalitas dan homogenitas populasi terhadap data prestasi belajar siswa. Uji normalitas dilakukan sebanyak 15 kali dan diperoleh $L_{\text {obs }}$ untuk masing-masing kelompok lebih kecil dari $L_{0,05 ; n}$ dengan $D K=\left\{L \mid L>L_{0,05 ; n}\right\}$, sehingga $L_{o b s} \notin D K$ dan $H_{o}$ diterima. Dengan demikian, diperoleh kesimpulan bahwa semua sampel pada penelitian ini berasal dari populasi yang berdistribusi normal. Untuk uji homogenitas variansi populasi, diperoleh bahwa $\chi_{\text {obs }}^{2}$ pada masing-masing kelompok lebih kecil dari $\chi_{\text {tabel }}^{2}$ dengan $D K=$ $\left\{\chi^{2} \mid \chi^{2}>\chi^{2}{ }_{0,05 ; 3-1}\right\}=\left\{\chi^{2} \mid \chi^{2}>5,9915\right\}$. Karena $\chi^{2}{ }_{o b s}$ berada di luar daerah kritis, maka $H_{0}$ diterima. Dengan demikian dapat disimpulkan bahwa populasi mempunyai variansi yang sama (homogen).

Tabel 1 berikut menyajikan rangkuman rerata data prestasi belajar matematika siswa berdasarkan model pembelajaran ditinjau dari self-efficacy.

Tabel 1. Rerata Data Prestasi Belajar Matematika Siswa pada Masingmasing Model Pembelajaran dan Self-efficacy

\begin{tabular}{ccccc}
\hline \multirow{2}{*}{ Model } & \multicolumn{3}{c}{ SELF-EFFICACY } & Rerata \\
\cline { 2 - 4 } & Tinggi & Sedang & Rendah & Marginal \\
\hline TPS & 80,2632 & 78,2353 & 77,4000 & 78,4211 \\
TTW & 76,6667 & 70,9677 & 74,7619 & 73,9362 \\
TSTS & 74,0909 & 69,6875 & 59,4737 & 69,6842 \\
Rerata Marginal & 76,1310 & 73,8596 & 72,1512 & \\
\hline
\end{tabular}

Pengujian hipotesis dilakukan untuk mengetahui apakah terdapat perbedaan pengaruh model pembelajaran dan self-efficacy serta interaksinya terhadap prestasi belajar matematika siswa. Rangkuman hasil perhitungan analisis variansi dua jalan dengan sel tak sama disajikan pada Tabel 2

Tabel 2. Rangkuman hasil perhitungan analisis variansi dua jalan dengan sel tak sama

\begin{tabular}{lcrrrrr}
\hline \multicolumn{1}{c}{ Sumber } & \multicolumn{1}{c}{$I K$} & $d k$ & \multicolumn{1}{c}{$R K$} & \multicolumn{1}{c}{$F_{\text {obs }}$} & $F_{\text {tabel }}$ & Keputusan \\
\hline Model (A) & 5005,9500 & 2 & 2502,9750 & 18,2523 & 3,086 & $H_{0 A}$ Ditolak \\
Self-efficacy (B) & 1784,4883 & 2 & 892,2446 & 6,5065 & 3,086 & $H_{0 B}$ Ditolak \\
Interaksi (AB) & 1944,2658 & 4 & 486,0665 & 3,5445 & 2,4045 & $H_{0 A B}$ Ditolak \\
Galat (G) & 37711,3623 & 275 & 137,1322 & & & \\
Total & 46446,0665 & 284 & & & & \\
\hline
\end{tabular}


Berdasarkan Tabel 2, maka diperoleh kesimpulan sebagai berikut. (1) Pada efek utama (A), $F_{A}=18,2523$ dengan $D K=\left\{F \mid F>F_{0,05 ; 2,275}\right\}=\{F \mid F>3,086\}$. Karena $F_{A}$ berada pada daerah kritis, maka $H_{0 A}$ ditolak. Hal ini berarti terdapat perbedaan pengaruh penggunaan model pembelajaran TPS, TTW, dan TSTS terhadap prestasi belajar $\begin{array}{lllll}\text { matematika siswa. (2) Pada efek utama } & \text { (B), } F_{B}=6,5065 \text { dengan }\end{array}$ $D K=\left\{F \mid F>F_{0,05 ; 2,275}\right\}=\{F \mid F>3,086\}$. Karena $F_{B}$ berada pada daerah kritis, maka $H_{0 B}$ ditolak. Hal ini berarti terdapat perbedaan yang signifikan pada kategori self-efficacy tinggi, sedang, dan rendah terhadap prestasi belajar matematika siswa. (3) Pada efek interaksi (AB), $F_{A B}=3,5445$ dengan $D K=\left\{F \mid F>F_{0,05 ; 4,275}\right\}=\{F \mid F>2,4045\}$. Karena $F_{A B}$ berada pada daerah kritis, maka $H_{0 A B}$ ditolak. Hal ini berarti terdapat interaksi antara model pembelajaran dan kategori self-efficacy terhadap prestasi belajar matematika siswa.

Hasil perhitungan anava menunjukkan bahwa $H_{O A}$ ditolak, sehingga dilakukan uji komparasi rerata antar baris yang menghasilkan $F_{1,-2}=6,9303>2 F_{0,05 ; 2,275}=6,0572$ $\left(H_{0} \quad\right.$ ditolak $), \quad F_{2,-3}=6,2291>2 F_{0,05 ; 2,275}=6,0572 \quad\left(H_{0} \quad\right.$ ditolak $), \quad$ dan $F_{1,-3 .}=26,4401>2 F_{0,05 ; 2,275}=6,0572\left(H_{0}\right.$ ditolak $)$. Selanjutnya, dengan melihat rerata marginal pada Tabel 1 dapat disimpulkan bahwa pembelajaran kooperatif TPS memberikan prestasi belajar matematika yang lebih baik daripada TTW dan TSTS, serta pembelajaran kooperatif tipe TTW memberikan prestasi belajar lebih baik daripada TSTS. Hasil penelitian ini sesuai dengan hipotesis penelitian yang diajukan. Lebih baiknya prestasi belajar matematika siswa yang dikenai model pembelajaran TPS disebabkan karena pada model pembelajaran kooperatif tipe TPS kelompok hanya terdiri dari dua orang siswa sehingga dengan anggota yang sedikit, siswa tidak akan malu bertanya dengan teman sebangkunya dan proses diskusi menjadi lebih efektif. Hasil penelitian ini juga didukung oleh penelitian yang dilakukan oleh Kitaoka (2013) jika dalam proses pembelajaran penggunaan TPS lebih efektif sehingga dapat meningkatkan kemampuan siswa. Selanjutnya, model pembelajaran TTW memberikan prestasi belajar matematika yang lebih baik daripada TSTS, pada proses pembelajaran TTW proses pembelajaran yang berlangsung lebih efektif daripada saat pembelajaran TSTS. Menurut Lie (2004: 47), kekurangan dari TSTS adalah membutuhkan lebih banyak waktu, sulit dalam membuat keputusan, kurang kesempatan untuk kontribusi individu sehingga pembelajaran TTW lebih baik daripada TSTS. 
Hasil perhitungan anava menunjukkan bahwa $H_{O B}$ ditolak, sehingga dilakukan uji komparasi rerata antar kolom yang menghasilkan $F_{.1-.2}=1,7775<2 F_{0,05 ; 2,275}=6,0572$ $\left(H_{0}\right.$ diterima),

$F_{.2-3}=1,0057<2 F_{0,05 ; 2,275}=6,0572$ diterima), dan $F_{.1-.3}=5,4862>2 F_{0,05 ; 2,275}=6,0572\left(H_{0}\right.$ ditolak $)$. Dari hasil perhitungan dapat disimpulkan prestasi belajar matematika siswa yang mempunyai self-efficacy tinggi sama dengan siswa yang mempunyai self-efficacy sedang, siswa dengan self-efficacy sedang sama dengan prestasi siswa self-efficacy rendah, dan prestasi belajar matematika siswa yang mempunyai self-efficacy tinggi lebih baik daripada siswa yang mempunyai selfefficacy rendah. Kesimpulan pada hipotesis ini tidak sesuai dengan hipotesis penelitian. Lebih baiknya prestasi belajar matematika siswa yang mempunyai self-efficacy tinggi karena self-efficacy dapat mempengaruhi siswa dalam memilih kegiatan belajar. Sesuai dengan pendapat Zulkosky (2009: 93) yang menyatakan bahwa self efficacy menentukan bagaimana siswa merasakan, berpikir, memotivasi diri mereka dan berperilaku. Siswa dengan kepercayaan yang tinggi memandang tugas-tugas yang sulit sebagai tantangan untuk menjadi lebih baik daripada bersikap menghindar. Hal ini sejalan dengan penelitian Bassi pada tahun 2007 (Santrock, 2011: 430) yang menunjukkan bahwa remaja dengan self-efficacy tinggi memiliki pencapaian akademik yang lebih tinggi, menghabiskan lebih banyak waktu untuk melakukan pekerjaan rumah, dan lebih mengasosiasikan kegiatan belajar dengan pengalaman. Berbeda dengan siswa yang mempunyai self-efficacy tinggi, siswa yang mempunyai self-efficacy rendah cenderung menghindari tugas, usaha yang dilakukan juga menurun serta mudah menyerah ketika menghadapi kesulitan. Hal ini didukung oleh pendapat Bandura bahwa siswa yang memiliki keyakinan diri rendah bahkan tidak mungkin mencoba belajar untuk ujian karena dia tidak percaya bahwa belajar akan sangat bermanfaat dan berguna baginya (Santrock, 2011: 236). Dengan demikian, prestasi belajar siswa dengan self-efficacy tinggi lebih baik daripada siswa dengan self-efficacy sedang dan rendah.

Selanjutnya, tidak terdapat perbedaan prestasi belajar matematika siswa yang mempunyai self-efficacy tinggi dan sedang, serta sedang dan rendah. Hal ini karena siswa dengan self-efficacy sedang dan rendah dalam penelitian ini merasa tertarik dan terlihat antusias dengan adanya model pembelajaran baru. Sesuai dengan pendapat Bandura (1999: 351), bahwa self-efficacy dipengaruhi oleh proses-proses psikologis antara lain proses kognitif (cognitive processes), proses motivasional (motivational processes), proses afektif (affective processes), proses seleksi/pemilihan (selection processes). Proses motivasional di sini mempengaruhi siswa self-efficacy sedang, sehingga mengakibatkan 
prestasi belajar matematika siswa self-efficacy tinggi sama dengan self-efficacy sedang dan self-efficacy sedang sama dengan siswa self-efficacy rendah.

Berdasarkan uji komparasi rerata antar sel pada baris yang sama diperoleh kesimpulan bahwa pada model pembelajaran kooperatif tipe TPS dan TTW, siswa dengan self-efficacy tinggi, sedang, dan rendah mempunyai prestasi belajar matematika yang sama baiknya. Kesimpulan pada hipotesis ini tidak sesuai dengan hipotesis penelitian yang diajukan. Adapun faktor penyebabnya adalah siswa merasa termotivasi dengan adanya model pembelajaran baru sehingga prestasi belajar siswa dengan self-efficacy tinggi, sedang, rendah sama baiknya. Pada model pembelajaran kooperatif tipe TSTS, tidak terdapat perbedaan prestasi belajar matematika antara siswa dengan self-efficacy tinggi dan sedang, sedang dan rendah. Kesimpulan hipotesis ini tidak sesuai dengan hipotesis penelitian yang diajukan yang menyatakan bahwa, pada model pembelajaran kooperaatif tipe TSTS, prestasi belajar matematika siswa dengan self-efficacy tinggi lebih baik daripada siswa dengan self-efficacy sedang dan rendah serta prestasi belajar matematika siswa dengan self-efficacy sedang lebih baik daripada siswa dengan selfefficacy rendah. Hal ini karena murid denga self-efficacy sedang dan rendah tertarik untuk belajar dikarenakan model pembelajaran yang cenderung baru bagi mereka dan belum pernah mereka coba sebelumnya. Sehingga prestasi siswa dengan self-efficacy rendah sama dengan siswa self-efficacy sedang dan prestasi siswa dengan self-efficacy sedang sama dengan siswa self-efficacy tinggi.

Berdasarkan uji komparasi rerata antar sel pada kolom yang sama diperoleh kesimpulan bahwa pada siswa dengan self-efficacy tinggi, model pembelajaran kooperatif tipe TPS, TTW, dan TSTS memberikan prestasi belajar matematika yang sama baiknya. Pada siswa dengan self-efficacy sedang, model pembelajaran kooperatif tipe TPS, TTW, dan TSTS memberikan prestasi yang sama baiknya. Kesimpulan pada hipotesis ini tidak sesuai dengan hipotesis penelitian yang diajukan. Ketidaksesuaian ini karena model pembelajaran yang belum pernah digunakan sehingga membuat siswa dengan selfefficacy sedang lebih termotivasi dalam proses pembelajaran sehingga berpengaruh pada self-efficacy siswa dan menyebabkan pada siswa dengan self-efficacy sedang pembelajaran TPS, TTW, dan TSTS menghasilkan prestasi belajar matematika sama baiknya. Pada siswa dengan self-efficacy rendah, model pembelajaran kooperatif tipe TPS sama baiknya dengan TTW, TPS lebih baik daripada TSTS, dan TTW lebih baik daripada TSTS. Kesimpulan ini tidak sesuai dengan hipotesis penelitian. Pada pembelajaran kooperatif tipe TPS dan TTW prestasi siswa dengan self-efficacy rendah bisa sama karena siswa cenderung termotivasi dan tertarik saat proses pembelajaran sehingga menghasilkan prestasi belajar yang sama. 


\section{SIMPULAN DAN SARAN}

Dari hasil penelitian di atas dapat disimpulkan sebagai berikut. (1) Model pembelajaran kooperatif tipe TPS memberikan prestasi belajar matematika yang lebih baik daripada model pembelajaran kooperatif tipe TTW dan TSTS. Model pembelajaran kooperatif tipe TTW memberikan prestasi belajar matematika yang lebih baik daripada model TSTS. (2) Prestasi belajar matematika siswa yang mempunyai self-efficacy tinggi sama baik dengan siswa yang mempunyai self-efficacy sedang. Prestasi belajar matematika siswa yang mempunyai self-efficacy sedang sama baik dengan siswa yang mempunyai self-efficacy rendah. Prestasi belajar matematika siswa yang mempunyai selfefficacy tinggi lebih baik dengan siswa yang mempunyai self-efficacy rendah. (3) Pada model pembelajaran kooperatif tipe TPS dan TTW prestasi belajar matematika siswa dengan self-efficacy tinggi, sedang, dan rendah sama baiknya. Pada model pembelajaran TSTS, prestasi belajar matematika siswa self-efficacy tinggi sama baiknya dengan siswa self-efficacy sedang, prestasi belajar matematika siswa self-efficacy sedang sama dengan siswa self-efficacy rendah, prestasi belajar matematika siswa self-efficacy tinggi lebih baik daripada siswa dengan self-efficacy rendah. (4) Pada siswa dengan self-efficacy tinggi dan sedang model pembelajaran kooperatif tipe TPS, TTW, dan TSTS memberikan prestasi belajar matematika sama baiknya. Pada siswa dengan self-efficacy rendah, model pembelajaran kooperatif tipe TPS dan TTW memberikan prestasi belajar matematika yang sama baiknya, model pembelajaran kooperatif tipe TPS memberikan prestasi belajar matematika yang lebih baik daripada TSTS, dan model pembelajaran kooperatif tipe TTW memberikan prestasi belajar matematika yang lebih baik daripada TSTS.

Saran dari hasil penelitian ini adalah, guru sebaiknya menerapkan model pembelajaran TPS sebagai salah satu referensi dalam pembelajaran di kelas. Dalam pembentukan kelompok, heterogenitas kemampuan akademik dan self-efficacy siswa perlu diperhatikan. Guru hendaknya mempersiapkan fasilitas, perangkat pembelajaran, dan pengkondisian siswa yang bisa mendukung proses pembelajaran dengan maksimal. Selain itu, bimbingan, dorongan, dan motivasi dari guru sangat diperlukan untuk membantu siswa dengan self-efficacy sedang dan rendah meningkatkan prestasi belajar matematikanya.

\section{DAFTAR PUSTAKA}

Abruscato, J. 1996. Teaching Children Science. USA: Allyn and Bacon.

Agus Suprijono. 2009. Cooperative Learning Teori dan Aplikasi PAIKEM. Yogyakarta: Pustaka Pelajar. 
Arends, R. I. 1997. Learning to Teach. New York: McGraw-Hill Companies.

Artut, P.D. 2010. Experimental Evaluation of the Effects of Cooperative Learning on Kindergarten Children's Mathematics Ability. International Journal of Education Research. 28 (2009). 370-80.

Badan Standar Nasional Pendidikan. 2014. Laporan Hasil Ujian Nasional Tahun Pelajaran 2013/2014.

Bandura, A. 1999. Self-efficacy in Changing Societies. New York: Cambridge University.

Dwi Sulisworo dan Fadiyah Suryani. 2014. The Effect of Cooperative Learning, Motivation and Information Technology Literacy to Achievement. International Journal of Learning \& Development. 4 (2). 58-64.

Huinker, D. and Laughlin, C. 1996. Talk Your Way Into Writing. Dalam Communication in Mathematics K-12 and Beyond, 1996 Year Book. The National Council of Teacher of Mathematics.

Judge, T. A., Shaw, J. C., Jackson, C. L., Scott, B. A., and Rich, B. L. 2007. Self-efficacy and Work-Related Performance: The Integral Role of Individual Differences. Journal of Applied Psychology. 92 (7). 107-129.

Karsten, R and Roberta, R. 1998. Computer Self-Efficacy: A Practical Indicator of Student Computer Competency in Introductory IS Courses. Journal of Informing Science. 1 (3): 61-68.

Kitaoka, H. 2013. Teaching Methods that Help Economics Students to be Effective Problem Solvers. International Journal of Arts and Commerce. 2 (1). 101-110.

Lie, A. 2004. Cooperative Learning: Mempraktikkan Cooperative Learning di RuangRuang Kelas. Jakarta: PT Grasindo.

Miftahul Huda. 2011. Cooperative Learning. Yogyakarta: Pustaka Pelajar.

Nana Sudjana. 2005. Dasar-Dasar Proses Belajar Mengajar. Bandung: Sinar Baru Algensindo Offset.

Pajares, F . 1996. Self-Efficacy in Academic Settings. American Educational Research Association. 39 (10): 2-39.

Pandya, S. 2011. Interactive effect of co-operative learning model and learning goals of students on academic achievement of students in mathematics. Mevlana International Journal of Education (MIJE). 1 (2). 27-34.

Santrock, J. W. 2011. Educational Psychology. New York: McGraw-Hill.

Springer, L., Stanne, M. E., and Donovan, S. S. 1999. Effect of Small Group Learning on Undergraduates in Science, Mathematics, Engineering, and Technology: A MetaAnalysis. Review ofEducational Research. 69 (1). 21-51.

Supriyono. 2011. Developig Mathematical Learning Device Using TTW (Think-TalkWrite) Strategy Assisted By Learning Cd To Foster Mathematical Communication.Procceding: International Seminar and the Fourth National 
Conference on Mathematics Education Yogyakarta State University. eprints.uny.ac.id.

Zimmerman, B.J. 2000. Self-Efficacy: An Essential Motive to learn. Contemporary Educational Psychology. 25 (2000). 82-91.

Zulkosky, K. 2009. Self-Efficacy: A Concept Analysis. Journal Compilation. 44: 93102. 